\title{
Antoine Berman, traduire une violence première
}

\author{
Rosie Pinhas-Delpuech*
}

J'ai traduit mon premier livre de l'hébreu en 1988. J'avais quarante ans, l'édition m'intimidait, pourtant j'ai trouvé le livre, l'éditrice et j'ai traduit. A fond, aveuglément, comme une planche de secours dans la mer, la nuit, et le clignotement d'un phare au loin. Rien n'a changé depuis.

Dix ans plus tard, en 1998, j'ai publié mon premier livre de fiction, Insomnia, une traduction nocturne. Il y était question d'une traductrice insomniaque et le livre portait en exergue deux phrases de L'Epreuve de l'étranger d'Antoine Berman :

Le pur traducteur est celui qui a besoin d'écrire à partir d'une œuvre, d'une langue et d'un auteur étrangers. Détour notable.

Dans la traduction, il y a quelque chose de la violence du métissage.

Ce premier livre et les deux phrases d'Antoine Berman énoncent un pacte fondateur entre la traduction/l'écriture et moi. Je ne le sais qu'aujourd'hui. Rien ne peut le rompre ni l'interrompre, il s'arrêtera avec moi.

Que s'est-il passé d'aussi fondateur pendant ces dix premières années de traduction pour qu'un tel engagement à vie se soit tramé à mon insu ? Presque contre mon gré. Je craignais que traduire m'empêche d'écrire : elle m'a conduite, pas à pas, à l'écriture et à la traduction. Par ce « détour » et cette « violence » qu'aucun écrivain n'a exprimé avec la force et l'urgence qui s'entendent dans la voix d'Antoine Berman.

Le français est ma langue, la langue de mon père, je suis née avec. Mais je l'ai parlé et appris au loin, à un carrefour géographique où beaucoup

\footnotetext{
* Directrice de la collection « Lettres hébraïques » aux éditions Actes Sud.
} 
de langues se croisaient, résonnaient entre elles, se faisaient écho. Arrivée en France à dix-huit ans, pour la jouer, la danser, l'amplifier, je me suis sentie corsetée, à l'étroit, entravée.

Je suis partie. J'ai découvert l'hébreu. Là aussi, presque à mon insu. Une langue ancienne, réactualisée, où résonnent d'autres langues, des parcours, des errances.

Plus tard, de retour en France, dans ce qui continuait encore de m'enserrer, j'ai fait un geste de salut : j'ai traduit aveuglément l'hébreu en français. Pour me faire une place dans la langue : pour faire une place à tout ce qui est irréductiblement étranger chez un individu, dans une langue, une culture, une civilisation.

Ce que je faisais m'était vital, mais à mesure que j'avançais, je voulais savoir pourquoi, comment, pourquoi moi, pourquoi cette langue et surtout pourquoi ce désormais mien métier si insaisissable?

J'ai rencontré Isabelle Berman vers 1995, au moment où ce questionnement qui émergeait d'une pratique était déjà mûr. Elle m'a parlé de l'œuvre de celui dont elle portait le nom. La découverte de la pensée bermanienne a été pour moi, comme une déflagration. Inégalée jusqu'à ce jour. Je continue de lire avec passion tous ceux - surtout écrivains/traducteurs, metteurs en scène, musiciens, tous ceux qui ont affaire à un texte et à sa lecture - qui écrivent sur la traduction.

Aucun ne donne corps de manière aussi totale qu'Antoine Berman, à mon expérience : le choc permanent, la violence de deux langues qui entrent en collision, le refus d'accueillir, la résistance des matériaux, la lutte, le corps à corps. Et la nécessité des cultures de se contraindre, se régenter, pour accueillir d'autres cultures, parce qu'il y va de la vie de chacun, de sa liberté de respirer.

Traduire est un acte essentiellement politique. Politique, de polis, cité, ville, espace public. Introduire l'étranger, lui faire de la place, coûte que coûte, sous toutes ses formes, corps nu, en haillons, puant, ou vêtu d'atours parfumés, autre, surprenant, dérangeant, effrayant, aimable, grimaçant. Travail épuisant de maraude pour le faire entrer souvent en contrebande dans la langue. Tous les jours d'une vie. 
Les années ont passé, j'écris/je traduis dans le même aveuglement, lucide désormais. Il n'y a pas longtemps, j'ai revu Isabelle Berman. Je voulais savoir des choses qu'Antoine Berman n'avait pas dites dans ses livres. Par pudeur, sans doute. Pourquoi l'espagnol d'Argentine ? Comment ? Qui était Berman le traducteur? Elle m'a raconté.

La découverte de l'Argentine, du tout d'un pays. Langue, odeur, son, musique, rue, gens, politique. Et la métamorphose d'un individu, d'un indivisible qui explose, se divise, s'ouvre et s'éparpille irrémédiablement. Après, il ne lui reste plus qu'à recoller ses morceaux en les traduisant. Sauvagement, violemment. Antoine Berman a traduit à fond, il a écrit de cet endroit même où se produit le choc, l'étincelle.

Paul Célan, le poète et traducteur, est arrivé en France après la guerre, il a épousé une femme qui s'appelait Gisèle de l'Estrange. Epouser une femme, sa langue, son estrangeté.

Vers la fin, m'a raconté Isabelle Berman l'Argentine, Antoine regrettait de ne pas avoir le temps de traduire. Sa vie brève a suffi à en saisir la fulgurance et à l'écrire.

Paris, le 5 mars 2021 